\title{
Characterization of aerosol pollution events in France using ground-based and POLDER-2 satellite data
}

\author{
M. Kacenelenbogen, J.-F. Léon, I. Chiapello, and D. Tanré \\ Laboratoire d'Optique Atmosphérique, Centre National de la Recherche Scientifique -Université des Sciences et Technologies \\ de Lille, Villeneuve d'Ascq, France
}

Received: 28 March 2006 - Published in Atmos. Chem. Phys. Discuss.: 12 July 2006

Revised: 20 September 2006 - Accepted: 23 October 2006 - Published: 26 October 2006

\begin{abstract}
We analyze the relationship between daily fine particle mass concentration (PM2.5) and columnar aerosol optical thickness derived from the Polarization and Directionality of Earth's Reflectances (POLDER) satellite sensor. The study is focused over France during the POLDER2 lifetime between April and October 2003. We have first compared the POLDER derived aerosol optical thickness (AOT) with integrated volume size distribution derived from ground-based Sun Photometer observations. The good correlation $(\mathrm{R}=0.72)$ with sub-micron volume fraction indicates that POLDER derived AOT is sensitive to the fine aerosol mass concentration. Considering 1974 match-up data points over 28 fine particle monitoring sites, the POLDER-2 derived AOT is fairly well correlated with collocated PM2.5 measurements, with a correlation coefficient of 0.55 . The correlation coefficient reaches a maximum of 0.80 for particular sites. We have analyzed the probability to find an appropriate air quality category (AQC) as defined by U.S. Environmental Protection Agency (EPA) from POLDER-2 AOT measurements. The probability can be up to $88.8 \%( \pm 3.7 \%)$ for the "Good" AQC and 89.1\% ( $\pm 3.6 \%)$ for the "Moderate" AQC.
\end{abstract}

\section{Introduction}

Atmospheric pollution due to airborne fine particles is an environmental issue of a worldwide increasing concern. Atmospheric aerosols also called Particulate Matter (PM) interact with the solar and thermal radiation and thus affect the Earth's radiative balance (Anderson et al., 2003). The PM mass measured at the ground level is a common way to quantify the amount of aerosol particles in the atmosphere and is used as a standard to evaluate air quality. PM monitoring is particularly important for human health protection

Correspondence to: M. Kacenelenbogen

(meloe@loa.univ-lille1.fr) because the exposure to suspended particles can contribute, among others, to some lung and respiratory diseases and even premature death. However, most of the air qualitymonitoring stations are located close to major urban areas leaving large areas without operational observations. Satellite remote sensing is well suited for a daily monitoring of the aerosol load (Kaufman et al., 2002; King et al., 1999). In the recent years several set of satellite data have fostered a comprehensive description of the temporal and spatial variability of different aerosol species, from anthropogenic aerosols (Tanré et al., 2001) to desert dust (Léon and Legrand, 2003). The monitoring of aerosols from space has also been widely used during this last decade for the evaluation of aerosol influence on global climate change through the impact on the Earth-atmosphere radiation budget (Boucher and Tanré, 2000; Bréon et al., 2002). Primary aerosol quantity derived from space borne remote sensors operating in the solar spectrum is the aerosol optical thickness. The relationship between column aerosol optical thickness (AOT) derived from satellite imagery and fine particulate mass ground measurements (PM) has already been explored over the United States (Engel-Cox et al., 2004; Wang and Christopher, 2003; AlSaadi et al., 2005) and other populated and industrialized regions in Asia ( $\mathrm{Li}$ et al., 2005) and Europe (Chu et al., 2003) using retrievals from the MODIS radiometer (MODerate Imaging Spectroradiometer, on board Earth Observing System (EOS) TERRA and AQUA satellites). Wang and Christopher (2003) have used a simple linear relationship between MODIS derived AOT and $24 \mathrm{hr}$ mean PM2.5 to quantitatively estimate air quality categories as defined by the U.S. Environmental Protection Agency (EPA) with an accuracy of more than $90 \%$ in cloud-free conditions.

POLDER (Polarization and Directionality of Earth's Reflectances) has flown aboard ADEOS-1 from November 1996 to June 1997 and aboard ADEOS-2 (that crosses the equator at 10:30 UTC) from April to October 2003. Despite the short life of the instrument, a unique set of observations

Published by Copernicus GmbH on behalf of the European Geosciences Union. 


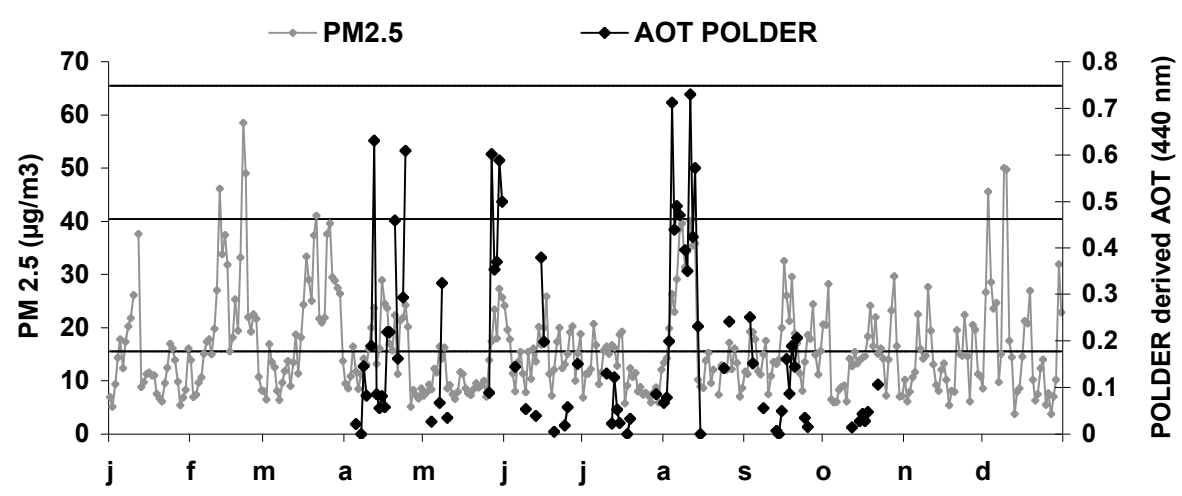

Fig. 1. Temporal evolution of 24-h averaged fine particulate mass concentration (PM2.5 in $\mu \mathrm{g} / \mathrm{m} 3$ ) during year 2003 over Lille (North of France). We show the different Air quality categories (according to the EPA) such as Good (between 0 and $15.4 \mu \mathrm{g} / \mathrm{m}^{3}$ ) and Moderate (between 15.5 and $40.4 \mu \mathrm{g} / \mathrm{m}^{3}$ ). The POLDER derived AOT at $440 \mathrm{~nm}$ over the PM2.5 site of Lille is also presented between April and October 2003.

on the global aerosol distribution has been acquired. No comparison studies between radiometer POLDER-2 and PM ground measurements have been achieved yet. The aim of this paper is to analyze the capacity of POLDER measurements in estimating aerosol pollution events and to investigate the possible use of satellite data for air quality monitoring. We base our analysis on the data collected by POLDER-2 on ADEOS-2 and collocated ground measurements in France from local air quality monitoring stations and Sun photometer sites of the AERONET/PHOTONS network.

\section{Satellite and ground-based data}

\subsection{Daily mean fine particulate mass PM2.5}

The Particulate mass concentration measured at the ground level (PM $x$ means the mass of particles with an aerodynamic diameter lower than $x \mu \mathrm{m}$ ) is a common way to quantify the amount of particles in the atmosphere and is used as a standard to evaluate air quality. The small aerosol component, PM2.5 in $\mu \mathrm{g} / \mathrm{m}^{-3}$, is of most concern to human health because it can be easily inhaled deep into the lungs. Therefore we chose to base our study on PM2.5 data more appropriate for health related studies than PM10 data. PM 2.5 are found in smoke and haze and generally result from combustion, including motor vehicles, power plants, residential wood burning, forest fires, and agricultural burning. In terms of aerosol pollution monitoring, particulate mass concentration is measured by several air quality agencies scattered over France and handled by the French Environment and Energy Management Agency (ADEME). The mass concentration of the PM fraction is determined continuously using a Tapered Element Oscillating Microbalance (TEOM, uncertainty of a few $\mu \mathrm{g} / \mathrm{m} 3$ on the PM values). There could be an underestimation of the PM values by the TEOM caused by the evaporation of ammonium-nitrate (Hodzic et al., 2005). We have centred our attention on the year 2003 in order to use the measurements recorded during the POLDER-2 observation period between April and October 2003. Moreover, during 2003, local air quality monitoring stations have recorded (over Paris and its outskirts) a slight increase in the mean level of fine particles even though the amount of fine particles had remained stable from 1998 to 2002. Figure 1 presents the temporal evolution of ground-based 24-h PM2.5 mass concentrations recorded in downtown Lille city in North of France during year 2003. In general, there are more particulate pollution events and of higher intensity during winter than during the rest of the year. Among the peaks recorded during year 2003, we observe on Fig. 1 an absolute PM2.5 maximum value in winter up to $60 \mu \mathrm{g} . \mathrm{m}^{-3}$ during February. In summer, the maximum (up to $40 \mu \mathrm{g} \cdot \mathrm{m}^{-3}$ ) is observed in August. To give an order of magnitude, the U.S. Environment Protection Agency (EPA) has established that the 24-hour averaged PM2.5 concentration must be less than $40.5 \mu \mathrm{g} . \mathrm{m}^{-3}$ for healthy conditions concerning the whole population (including special groups such as elderly and children). We can observe on Fig. 1 that this $40.5 \mu \mathrm{g} \cdot \mathrm{m}^{-3}$ threshold has been exceeded 6 times during the whole winter period. Taking into account the assumed well mixed aerosols in the boundary layer, the increase of concentration of pollutants at ground level in winter could be explained by an inversion layer trapping aerosols underneath a "thermal lid" (a significant decrease of ground temperature values by night tend to induce a lower morning air temperature at the ground than at high altitude).

\subsection{Evaluation of the POLDER-2 aerosol optical thickness}

POLDER provides measurements of the spectral, directional and polarized characteristics of the solar radiation reflected by the Earth-Atmosphere system. POLDER-2's 
spatial resolution is $6 \mathrm{~km} \times 7 \mathrm{~km}$ and its wide field of view induces a $2400 \mathrm{~km}$ swath that allows a nearly global daily coverage. To increase the signal to noise ratio, the algorithm is applied to $3 \times 3$ POLDER pixels, leading to a resolution in the aerosol AOT of $21 \mathrm{~km} \times 18 \mathrm{~km}$. AOT retrieval from the POLDER polarized measurements is described by Deuzé et al. (2001). The AOT is retrieved at the $670 \mathrm{~nm}$ and $865 \mathrm{~nm}$ channels equipped with polarized filters. Only cloud-free pixels selected according to the cloud-screening algorithm of Bréon and Colzy (1999) are processed. The surface contribution is modelled as a semi-empirical bidirectional polarized distribution function that depends on the normalized difference vegetation index (NDVI) and the geo-type of the pixel according to the IGBP classification (Nadal and Bréon, 1999). Ten mono-modal lognormal size distributions are considered with corresponding effective radius from 0.05 to $0.15 \mu \mathrm{m}$ and a standard deviation of 0.403 for a complex refractive index of 1.47-0.01 i. In this study, we consider the AOT at $440 \mathrm{~nm}$ extrapolated from the measurements at 670 and $865 \mathrm{~nm}$. Physical AOT values are considered to be valid down to 0 . Figure 1 shows along with the PM2.5 measurements the corresponding POLDER derived AOT over the site of Lille, France between April and October 2003. Generally, the temporal trend in the optical thickness is very similar to the trend directly recorded in ground-based PM2.5, especially in August. However, some days show a peak of POLDER AOT not recorded at the ground by the PM measurements like on 27 May (POLDER AOT $=0.60$ and PM2.5 $=15.5 \mu \mathrm{g} / \mathrm{m} 3$ ). This could be due to the presence of a high altitude aerosol plume. On another hand, days like the 15th of April present a strong local PM value $(29 \mu \mathrm{g} / \mathrm{m} 3)$ not observed by POLDER-2 (AOT=0.08). This phenomenon could be due to the coarse resolution of the POLDER-2 instrument compared to the local station, or the choice of selecting daily mean PM2.5 compared to instantaneous POLDER-2 data. We can notice the difference in the number of observations between the ground-based PM2.5 (213 observations over the POLDER-2 operating period) and the satellite (78 observations) due to the impact of the cloud cover. As we focus on the capacity of POLDER to derive information on the particle mass, we first consider the comparison of POLDER derived AOT with integrated volume size distribution. For this purpose we use the data collected by the globally distributed AErosol RObotic NETwork (AERONET) (Holben et al., 1998) hardware, which consists in more than 140 identical automatic sun-sky scanning spectral radiometers. The aerosol size distribution (between 0.05 and $15 \mu \mathrm{m}$ ) and optical parameters (single scattering albedo, volume concentration, refractive index, and effective radius) are derived from the angular distribution of sky radiances measured in the almucantar according to the algorithm developed by Dubovik and King (2000). In this work, we use level 1.5 AERONET data (Smirnov et al., 2002) and the retrievals of the volume size distribution of aerosols derived from AERONET are selected with the highest possible accuracy according to

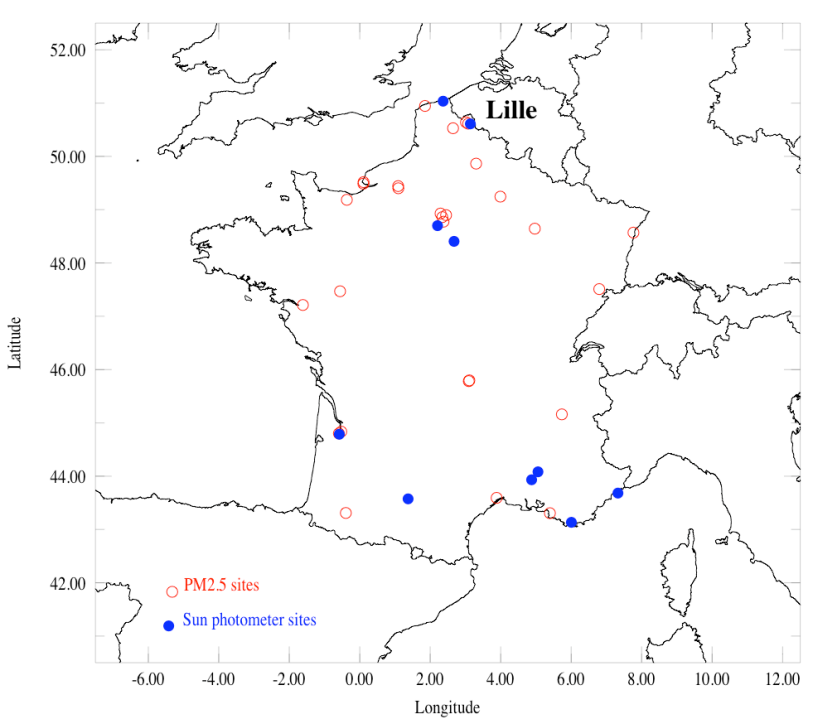

Fig. 2. Locations of (Red dots) the 28 PM2.5 stations and (Blue dots) the 10 AERONET/PHOTONS Sun photometer sites used in this study.

Dubovik et al. (2000). As we use daily average PM2.5, we have also compared the POLDER derived AOT with daily mean Sun photometer volume size distribution. Considering daily average rather than instantaneous observations may introduce a bias in the comparison. However, the difference between the satellite instantaneous observation and daily average AOT for urban/industrial area remains less than $10 \%$ (Smirnov et al., 2002). POLDER-2 data are averaged within a $3 \times 3$ pixels size area $\left(0.6^{\circ}\right)$ centred on the AERONET site of interest. During the POLDER-2 lifetime, 10 Sun photometers from the AERONET/PHOTONS network were operating over France. Their geographical locations are displayed on Fig. 2. We have compared the POLDER derived AOT and integrated volume size distribution from April to October 2003, providing a total of 473 match-up data points. The correlation (see Fig. 3) between the two quantities is enhanced from 0.66 to 0.72 when considering a cut-off radius of $1.0 \mu \mathrm{m}$, roughly corresponding to the PM2.5 physical cutoff radius. This is consistent with the fact that polarization by aerosol mainly comes from small spherical particles in the accumulation mode (Vermeulen et al., 2000). It indicates that POLDER derived AOT is well suited for remote sensing of fine mode particles.

\section{Comparison between POLDER-2 derived AOT and PM2.5 mass}

We have compared the satellite data to ground-based 24$\mathrm{h}$ mean PM2.5 measurements over France during the active POLDER-2 period. The locations of the PM2.5 stations are displayed on Fig. 2. The POLDER-2 AOT at 
Table 1. Statistics over 10 bins of 197 match-up points between POLDER AOT at $440 \mathrm{~nm}$ and PM2.5 (data shown in Fig. 5). The two first columns correspond to the minimum and the maximum aerosol optical thickness (AOT) for each of the 10 bins. The third and the forth columns respectively show, for each bin, the fraction of the corresponding PM2.5 values that fit into the AQC "good" $\left(\mathrm{PM} 2.5 \leq 15.4 \mu \mathrm{g} . \mathrm{m}^{-3}\right)$ and AQC "moderate" $\left(15.5 \mu \mathrm{g} \cdot \mathrm{m}^{-3} \leq \mathrm{PM} 2.5 \leq 40.4 \mu \mathrm{g} \cdot \mathrm{m}^{-3}\right)$. The last column shows the $90 \%$ level confidence interval on the population of associated AOT and PM2.5 values.

\begin{tabular}{lllll}
\hline AOT Min. & AOT Max. & AQC “Good" & AQC “Moderate” & Error $(\%)$ \\
\hline 0.00 & 0.01 & 88.8 & 11.2 & 3.7 \\
0.01 & 0.03 & 80.7 & 19.3 & 4.6 \\
0.03 & 0.05 & 65.0 & 35.0 & 5.6 \\
0.05 & 0.07 & 66.5 & 33.5 & 5.5 \\
0.07 & 0.10 & 64.5 & 35.5 & 5.6 \\
0.10 & 0.13 & 52.8 & 47.2 & 5.9 \\
0.13 & 0.17 & 56.3 & 43.7 & 5.8 \\
0.17 & 0.24 & 33.0 & 67.0 & 5.5 \\
0.24 & 0.34 & 28.4 & 70.1 & 5.4 \\
0.34 & 0.99 & 8.0 & 89.1 & 3.6 \\
\hline
\end{tabular}

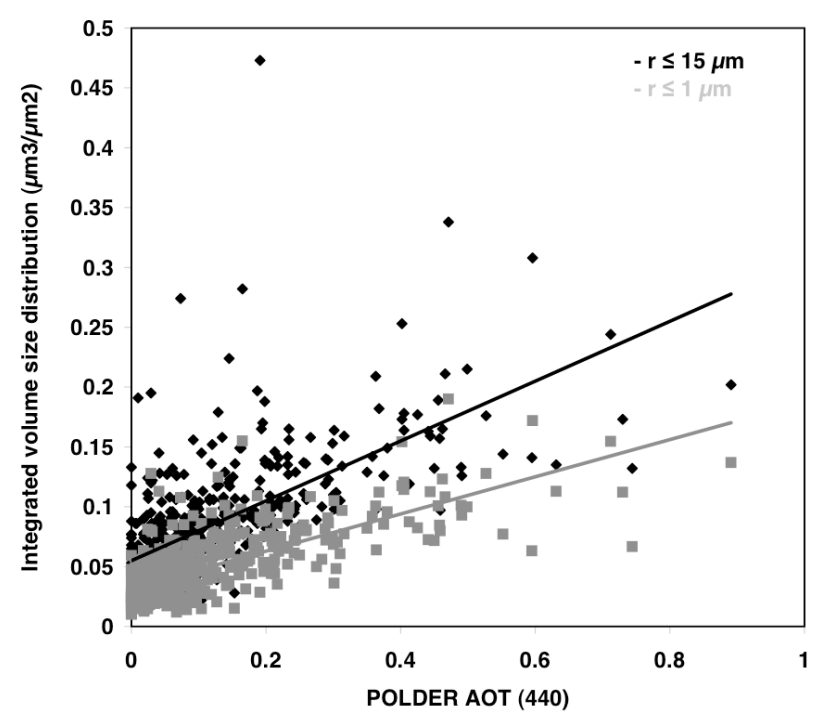

Fig. 3. Regression lines between POLDER derived AOT at 440 $\mathrm{nm}$ and Sun photometer integrated size distribution for the total size distribution ( $\mathrm{r} \leq 15 \mu \mathrm{m}$ in black, Volume concentration $=0.25$ AOT POLDER + 0.05, R=0.66, RMS=0.04) and the submicron fraction $(\mathrm{r} \leq 1 \mu \mathrm{m}$ in grey, Volume concentration $=0.15$ AOT POLDER + 0.03, $\mathrm{R}=0.72, \mathrm{RMS}=0.02$ ) over 10 selected AERONET/PHOTONS sites $(\mathrm{N}=473)$.

$440 \mathrm{~nm}$ are averaged in a $3 \times 3$ pixels size area (corresponding to $60 \times 60 \mathrm{~km}^{2}$ ) centred on the PM2.5 station of interest. Among the 35 stations available, 7 are classified as strongly affected by local car traffic and not considered in this study. The overall match-up database corresponds to 1974 comparison points. 5 stations among the 28 stations show a correlation coefficient over 0.70 . Fig. 4 gives an example of the regression found for the station of Lille, corre-

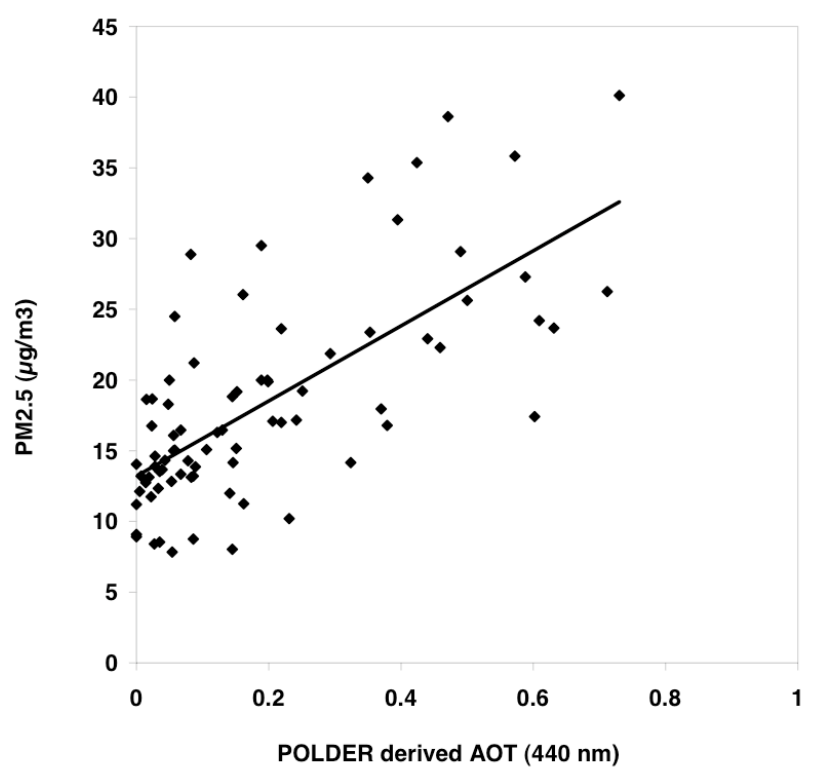

Fig. 4. Comparison between collocated daily averaged PM2.5 and POLDER derived AOT at $440 \mathrm{~nm}$ for a station close to the city of Lille from April to October $2003\left(\mathrm{PM}_{2.5}=26.56\right.$ AOT POLDER +13.20, $\mathrm{R}=0.70, \mathrm{~N}=78, \mathrm{RMS}=5.28$ ).

sponding to the data presented in Fig. 1. A significant offset of $13 \mu \mathrm{g} \cdot \mathrm{m}^{-3}$ indicates that the satellite has a limited capacity for monitoring small amounts of particles. For each site of the overall 28 stations, the slope of the regression remains between 15 and $40 \mu \mathrm{g} \cdot \mathrm{m}^{-3} /$ AOT unit and the offset between 8.4 and $16.1 \mu \mathrm{g} . \mathrm{m}^{-3}$. The overall comparison is presented in Fig. 5. When considering all of the 28 stations, the correlation coefficient is 0.55 . The slope of the regression is about $26 \mu \mathrm{g} . \mathrm{m}^{-3}$ per unit AOT, and we can still observe a significant offset close to $12 \mu \mathrm{g} \cdot \mathrm{m}^{-3}$. 
The comparison of this first relationship between POLDER AOT and PM2.5 with those previously established by using MODIS is complicated by the influence of several factors, like using PM10 instead of PM2.5 (Chu et al., 2003; Li et al., 2005), different wavelengths and spatial resolutions for the satellite AOT (Engel-Cox et al., 2004; Wang and Christopher, 2003), different time periods, and alternative approaches forcing the offset of the PM/Satellite AOT relationship through 0 . Additionally the difference of sensitivity of the two sensors to fine particles, and their different inversion algorithm for the AOT might have a significant impact on their relationship with PM2.5. Despite these limitations, the slope $\left(26 \mu \mathrm{g} . \mathrm{m}^{-3}\right.$ per unit AOT) and offset $\left(12 \mu \mathrm{g} . \mathrm{m}^{-3}\right)$ we have derived from POLDER are in the same range than those established by Engel Cox et al. (2004) between MODIS AOT and PM2.5 over the United States between April and September 2002 (slope of $19 \mu \mathrm{g} . \mathrm{m}^{-3}$, offset around $8 \mu \mathrm{g} \cdot \mathrm{m}^{-3}$ ). Other studies using MODIS found higher values for the regression slopes like, for example, the local study by Wang and Christopher (2003) over Alabama (slope $\sim 71 \mu \mathrm{g} . \mathrm{m}^{-3}$ per unit of MODIS AOT using PM2.5), or the comparison by Chu et al. (2003) over northern Italy (slope $\sim 55 \mu \mathrm{g} . \mathrm{m}^{-3}$ per unit of AERONET AOT using PM10). Further investigations should be performed to interpret these differences and evaluate the impacts of POLDER-2's coarser spatial resolution $(21 \times 18 \mathrm{~km})$ compared to MODIS (Level 2 MODIS's aerosol product is $10 \times 10 \mathrm{Km}$ ), and POLDER-2's sensitivity to fine particles on these AOT/PM relationships.

In our study, when data are arranged by bins of 197 points each (the last bin contains 201 points), the correlation coefficient rises up to 0.99 (also displayed on Fig. 5). Based on the bin averaged data set, we have assessed POLDER's capacity to estimate the EPA Air Quality Categories (AQC, see Wang and Christopher, 2003) over France for the 28 stations. Due to the relatively low PM2.5 values in our data set, it is only possible to consider the two first categories, i.e. below $15.5 \mu \mathrm{g} \cdot \mathrm{m}^{-3}$ (classified as "good") and between $15.5 \mu \mathrm{g} . \mathrm{m}^{-3}$ and $40.4 \mu \mathrm{g} \cdot \mathrm{m}^{-3}$ (classified as "moderate"). Table 1 presents the minimum and maximum AOT for each of the 10 bins as well as the percentage of the corresponding PM2.5 values that fit into the two respective EPA categories. Few points exceed $40.5 \mu \mathrm{g} . \mathrm{m}^{-3}$ in the last two bins, respectively $1 \%$ and $3 \%$ of the data. Concerning the other bins, $100 \%$ of the points are below $40.5 \mu \mathrm{g} . \mathrm{m}^{-3}$. The error is given for a $90 \%$ confidence level. For very low optical thickness (first bin, AOT <0.01), 88.8\% of the points are in the AQC labelled "good". Considering AOT above 0.35 the probability to have PM2.5 in the AQC "moderate" is $89.1 \%$. Since we are lacking values above $40.5 \mu \mathrm{g} \cdot \mathrm{m}^{-3}$, we cannot establish an upper limit for the AOT in the "moderate" AQC. For a POLDER AOT up to 0.10 , the averaged probability to find a corresponding PM2.5 below $15.5 \mu \mathrm{g} . \mathrm{m}^{-3}$ is $73 \%$. Below a threshold of 0.17 for the POLDER AOT, this probability is $68 \%$. If we also consider this threshold as a lower value for the "Moderate" AQC, the probability to have

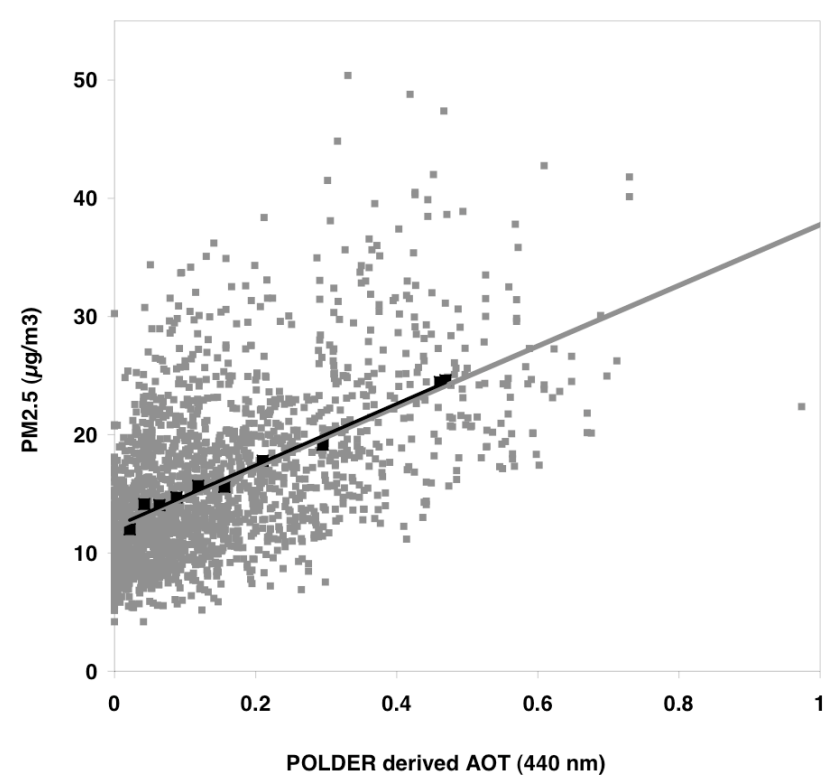

Fig. 5. Regression line between daily POLDER derived AOT at 440 $\mathrm{nm}$ and PM2.5 measured at the ground (Grey dots, $\mathrm{PM}_{2.5}=25.67$ AOT POLDER +12.10, $\mathrm{R}=0.55, \mathrm{~N}=1974, \mathrm{RMS}=5.53$ ) over $28 \mathrm{PM}$ stations in France from April to October 2003 and considering the mean values of each of the 10 bins (Black squares, $\mathrm{PM}_{2.5}=26.57$ AOT POLDER +12.21, $\mathrm{R}=0.99, \mathrm{~N}=10$, RMS = 0.57).

POLDER AOT that corresponds to a PM2.5 concentration between $15.5 \mu \mathrm{g} . \mathrm{m}^{-3}$ and $40.4 \mu \mathrm{g} . \mathrm{m}^{-3}$ is $75.4 \%$. POLDER observations are performed only in cloud-free conditions. In consequence, there are much less POLDER observations than PM2.5 data for a given site. If we consider the 28 stations, we have 2577 POLDER observations against 4573 for PM2.5 measurements from April to October, i.e. a ratio between the two data sets of $56 \%$. The number of PM2.5 observations that exceed the $15.5 \mu \mathrm{g} . \mathrm{m}^{-3}$ threshold is 1497 while the number of values of POLDER AOT above 0.17 is 817 . However, we have estimated the relative difference between the number of PM2.5 and POLDER AOT observations assessed to be in the "Moderate" AQC, computed according to Eq. (1):

$\varepsilon$ mod erate $=$

$\left(\frac{\sum_{\text {Nstation }} N b\left(\mathrm{PM}_{2.5} \geq 15.5 \mu \mathrm{g} / \mathrm{m}^{3}\right)}{\sum_{\text {Nstation }} N b\left(\mathrm{PM}_{2.5}\right)}-\frac{\sum_{\text {Nstation }} N b\left(\mathrm{AOT}_{\mathrm{POLDER}} \geq 0.17\right)}{\sum_{\text {Nstation }} N b\left(\mathrm{AOT}_{\mathrm{POLDER}}\right)}\right)$

Where $\varepsilon_{\text {moderate }}$ is the relative difference between both kind of measurements and $\mathrm{Nb}$ is the number of observations for each PM station, numbered from 1 to Nstation (28 over France). We have evaluated $\varepsilon_{\text {moderate }}$ to $1 \%$. As we observe a very weak underestimation in the number of observations assessed to be in the "Moderate" AQC by the POLDER AOT, the threshold of 0.17 seems adequate to statistically estimate the number of days that exceed the $15.5 \mu \mathrm{g} . \mathrm{m}^{-3}$ threshold. 


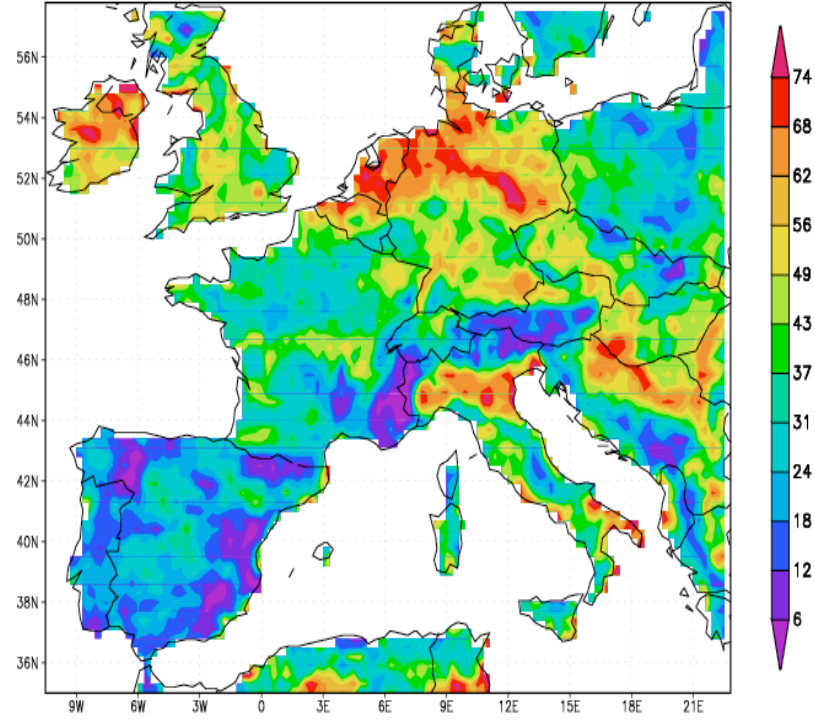

Fig. 6. Number of daily observations with a POLDER AOT above 0.17 and given as a percentage of the total number of observations during the POLDER-2 period (April-October 2003).

It should be noted that this threshold is based on a 7-month period from April to October 2003 and might be different in winter conditions. Moreover, the relationship between column aerosol optical thickness derived from satellite imagery and fine particulate mass ground-based measurements (PM2.5) is not straightforward and depends on the vertical resolution of the particles and their optical and microphysical properties. To those uncertainties should be added the ones on both type of measurements. In the case of the satellite inversion algorithm, there could be a major influence of the surface representation, the different aerosol model and the spatial resolution. Furthermore, to obtain our POLDER threshold for PM2.5 AQC assessment we have used several groundbased stations scattered over France associated to moderate aerosol loads but it should be validated over a broader area, especially over the most polluted regions of the world like Asia. Applying this threshold to all POLDER AOT over Western Europe allows to derive a map (see Fig. 6) of the percentage of days in the Moderate AQC during the period of April to October 2003. We can notice on Fig. 6 that POLDER shows that the main industrial areas of Western Europe, like the Netherlands, North Germany or Northern Italy are characterized by the highest frequency of days with Moderate air quality.

\section{Conclusions}

We have used for the first time 7 months of POLDER-2 retrieved AOT over France in 2003 to characterize aerosol pollution load at the ground on a regional scale. POLDER AOT retrieval algorithm over land is based on the measurement of the linear polarization of the light backscattered to space. The algorithm is particularly sensitive to aerosol particles in the accumulation mode that polarize the signal. Based on a comparison with Sun photometer derived volume size distribution, we show that POLDER derived AOT is well correlated to the atmospheric aerosol submicron volume fraction. This capacity to monitor the aerosol fine fraction is confirmed by the significant correlation obtained when comparing directly the POLDER derived AOT with ground-based PM2.5 data. The comparison between collocated daily averaged PM2.5 and POLDER derived AOT shows a lot of scattering, which might be due to the influence of the vertical distribution of the aerosol in the atmosphere. However, we find a significant correlation between POLDER AOT and PM2.5 over the 28 stations considered in this study. We have statistically tested the ability of the POLDER AOT measurements to assess the two first EPA Air Quality Categories. The lack of higher PM2.5 concentrations in our data set prevents us from studying the other AQC. For the first AQC, the frequency of occurrence of daily PM2.5 below $15.5 \mu \mathrm{g} . \mathrm{m}^{-3}$ is decreasing as a function of the POLDER AOT. We have assessed that a threshold of 0.17 for the POLDER AOT can be used to estimate the frequency of days showing a "Moderate" AQC. A further validation of this estimate still needs to be carried on at a broader scale, especially for the regions of the world the most affected by particle air pollution. It should also be mentioned that our study is limited to the period of POLDER-2's lifetime between April-October 2003, and that both PM/AOT relationships and POLDER AOT threshold for estimating AQC might be significantly different in the winter season. The winter season is generally characterized by a shallow boundary layer, leading to an increase of the slope of the regression between PM2.5 and AOT while the given threshold for the Moderate AQC should be lower. Moreover, a comprehensive investigation of the impact of the vertical distribution of aerosols in the relationship between groundbased PM2.5 and AOT measurements is now required to better analyze the capability of POLDER or other space-based passive remote sensors observations in estimating aerosol pollution events.

Acknowledgements. The French space agency, CNES and the Nord-Pas-De-Calais regional council support this research. We thank ADEME for providing the PM2.5 data and the AERONET/PHOTONS network for the Sun photometer data. This work is within the frame of the Institut de Recherche en Environnement Industriel (IRENI).

Edited by: F. J. Dentener 


\section{References}

Al Saadi, J., Szykman, J., Pierce, R. B., Kittaka, C., Neil, D., Chu, D. A., Remer, L. A., Gumley, L., Prins, E., Weinstock, L., MacDonald, C., Wayland, R., Dimmick, F., and Fishman, J.:, Improving national air quality forecasts with satellite aerosol observations, Bull. Am. Meteorol. Soc., 1249-1261, doi:10.1175/BAMS-86-9-1249, 2005.

Anderson, T. L., Charlson, R. J., Schwartz, S. E., Knutti, R., Boucher, O., Rodhe, H., and Heintzenberg, J.: Climate forcing by aerosols - A hazy picture, Science, 300, 1103-1104, 2003.

Boucher, O. and Tanré, D.: Estimation of the aerosol perturbation to the Earth's radiative budget over oceans using POLDER satellite aerosol retrievals, Geophys. Res. Lett., 27, 1103-1106, 2000.

Bréon, F.-M. and Colzy, S.: Cloud detection from the spaceborne POLDER instrument and validation against surface synoptic observations, J. Appl. Meteorol., 36, 777-785, 1999.

Bréon, F.-M., Tanré, D., and Generoso, S.: Aerosol effect on cloud droplet size monitored from satellite, Science, 295, 834-838, 2002.

Chu, D. A., Kaufman, Y. J., Zibordi, G., Chern, J. D., Mao, J., Li, C., and Holben, B. N.: Global monitoring of air pollution over land from Earth Observing System-Terra Moderate Resolution Imaging Spectroradiometer (MODIS), J. Geophys. Res., 108, doi:10.1029/2002JD003179, 2003

Deuzé, J.-L., Bréon, F.-M., Devaux, C., Goloub, P., Herman, M., Lafrance, B., Maignan, F., Marchand, A., Nadal, F., Perry, G., and Tanré, D.: Remote sensing of aerosols over land surfaces from POLDER-ADEOS-1 polarized measurements, J. Geophys. Res., 106, 4913-4926, 2001.

Dubovik, O. and King, M. D.: A flexible inversion algorithm for retrieval of aerosol optical properties from sun and sky radiance measurements, J. Geophys. Res., 105(D16), 20 673-20 696, 2000.

Dubovik, O., Smirnov, A., Holben, B. N., King, M. D., Kaufman, Y. J., Eck, T. F., and Slutsker, I.: Accuracy assessments of aerosol optical properties retrieved from Aerosol Robotic Network (AERONET) Sun and Sky radiance measurements, J. Geophys. Res., 105(D8), 9791-9806, 2000.

Engel-Cox, J. A., Holloman, C. H., Coutant, B. W., and Hoff, R. M.: Qualitative and quantitative evaluation of MODIS satellite sensor data for regional and urban scale air quality, Atmos. Environ., 38, 2495-2509, doi:10.1016/j.atmosenv.2004.01.039, 2004.
Hodzic, A., Vautard, R., Bessagnet, B., Lattuati, M., and Moreto, F.: Long-term urban aerosol simulation versus routine particulate matter observations, Atmos. Environ., 5851-5864, 2005

Holben, B. N., Eck, T. F., Sluster, I., Tanré, D., Buis, J. P., Setzer, A., Vermote, E., Reagan, J. A., Kaufman, Y. J., Nakajima, T., Lavenu, F., Jankowiak, I., and Smirnov, Z.: AERONET-A federated instrument network and data archive for aerosol characterisation, Rem. Sens. Environ., 66, 1-16, 1998.

Kaufman, Y. J., Tanré, D., and Boucher, O.: A satellite view of aerosols in the climate system, Nature, 419, 215-223, 2002.

King, M. D., Kaufman, Y. J., Tanré, D., and Nakajima, T.: Remote sensing of tropospheric aerosols from space: past present and future, Bull. Am. Meteorol. Soc., 80(11), 2229-2259, 1999.

Léon, J.-F. and Legrand, M.: Mineral dust sources in the surrounding of the North Indian Ocean, Geophys. Res. Lett., 30(6), 1309, doi:10.1029/2002GL016690, 2003.

Li, C., Lau, A. K., Mao, J., and Chu, D. A.: Retrieval, validation, and application of the 1-Km aerosol optical depth From MODIS measurements over Hong Kong, EEE Trans. Geosci. Remote Sens., 43(11), 2650-2658, 2005.

Nadal, F. and Bréon, F. M.: Parametrisation of surface polarised reflectance derived from POLDER spaceborne measurements, IEEE Trans. Geosci. Remote Sens., 37, 1709-1718, 1999.

Smirnov, A., Holben, B. N., Eck, T. F., Slutsker, I., Chatenet, B., and Pinker, R. T.: Diurnal variability of aerosol optical depth observed at AERONET (Aerosol Robotic Network) sites, Geophys. Res. Lett., 29(23), 2115, doi:10.1029/2002GL016305, 2002.

Tanré, D., Bréon, F.-M., Deuzé, J.-L., Herman, M., Goloub, P., Nadal, F., and Marchand, A.: Global observation of anthropogenic aerosols from satellite, Geophys. Res. Lett., 28(24), 4555-4558, 2001.

Vermeulen, A., Devaux, C., and Herman, M.: Retrieval of the scattering and microphysical properties of aerosols from groundbased optical measurements including polarization. I. Method, Appl. Opt., 39(33), 6207-6220, 2000.

Wang, J. and Christopher, S. A.: Intercomparison between satellitederived aerosol optical thickness and PM2.5 mass: Implications for air quality studies, Geophys. Res. Lett., 30(21), 2095, doi:10.1029/2003GL018174, 2003. 